\title{
Mycoplasma pneumoniae and the aetiology of lobar pneumonia in northern Nigeria
}

\author{
J T MACFARLANE, ${ }^{1}$ D S ADEGBOYE, ${ }^{2}$ AND M J WARRELL ${ }^{3}$ \\ From the Departments of Medicine ${ }^{1}$ and Veterinary Pathology and Microbiology, ${ }^{2}$ Ahmadu Bello \\ University, Zaria, Nigeria, and the Department of Virology, ${ }^{3}$ Churchill Hospital, Oxford UK
}

ABSTRACT Over a six-month period we studied 74 adult Nigerians who presented consecutively to Ahmadu Bello University Teaching Hospital, Zaria, with lobar or segmental pneumonia. Pneumococcal infection was diagnosed in $50 \%$ by the detection of pneumococcal polysaccharide antigen in serum or purulent sputum: $24 \%$ had pneumococcal antigenaemia. Twelve patients had evidence of Mycoplasma pneumoniae infection and half of these also had pneumococcal infection. The suggestion that $M$ pneumoniae respiratory infection may predispose to serious bacterial pneumonia is discussed. The initial clinical and radiological features were similar in the pneumococcal and $M$ pneumoniae groups. Raised cold agglutinin titres were not a reliable indication of $M$ pneumoniae infection, perhaps due to altered autoantibody production in Nigerians. Pneumonia was commoner in the dry season, probably related to depressed nasopharyngeal defences caused by drying. Less common causes of lobar pneumonia that were found are also discussed and no cases of legionnaires' disease were identified.

Lobar pneumonia continues to be one of the most important illnesses encountered in developing countries, being the commonest cause of hospital admissions in Zaria, Nigeria (Warrell, 1975), and in New Guinea (Douglas and Devitt, 1973). Nearly 700000 cases of pneumonia were reported to the National Research Council Survey in 1957, 50\% coming from Africa alone (National Academy of Science, 1962). A death rate of $20 \%$ has been reported from Nigeria despite antibiotics (Sofowara and Onadeko, 1973).

Streptococcus pneumoniae is the usual cause of lobar pneumonia in Africa (Tugwell and Greenwood, 1975). However, the fact that between $10 \%$ (Douglas and Riley, 1970; Sutton et al, 1970) and $31 \%$ (Tugwell and Greenwood, 1975) of patients with lobar pneumonia in the tropics do not respond promptly to penicillin suggests that other micro-organisms may also be implicated.

Mycoplasma pneumoniae is recognised as a significant cause of lower respiratory tract infections, accounting for $10 \%$ (Chanock, 1965) to $15 \%$ (Foy et al, 1970) of such infections in American civilian populations. Mycoplasma pneumoniae has a wide geographical distribution (Chanock et al, 1967) causing $28 \%$ of atypical pneumonias in Tokyo (Kitamoto et al, 1966) and 15\% in India (Gupta et al, 1975). It is also common among Chinese (Tai and Wei, 1976). Although $M$ pneumoniae infection has been reported from South Africa (Joosting et al, 1975) and Egypt (Hassan et al, 1972), there are no clinical studies of its importance as a cause of lobar pneumonia in tropical Africa.

In an environment where treatment and followup are difficult, it is vital to know the likely aetiology of common infections. Thus we have performed a prospective clinical and laboratory study of the cause of lobar pneumonia in Zaria in northern Nigeria, with particular emphasis on pneumococcal and $M$ pneumoniae infection.

\section{Methods}

Seventy-four Nigerian patients presenting consecutively to Ahmadu Bello University Teaching Hospital between August 1977 and January 1978 with clinical and radiological features of lobar or segmental pneumonia were seen by one of us. There were 60 men and 14 women, mean age 28.5 years $( \pm 12.6 \mathrm{SD})$. Two patients with acute respiratory illnesses and pleural effusions were included. A full history was taken, all patients were examined, and after other investigations most patients received parenteral penicillin. 
Twenty-six patients had received antibiotics before being seen. Patients attended a special follow-up clinic two to four weeks after initial presentation.

Investigations on all patients included a posteroanterior and lateral chest radiograph and haemoglobin and white cell count by standard methods. Haemoglobin electrophoresis showed no patients with sickle cell disease (SS) but 13 patients with sickle cell trait (AS).

A specimen of purulent sputum and all serum samples were tested for pneumococcal polysaccharide antigen by the countercurrent immunoelectrophoresis (CIE) method using pneumococcal omniserum (Tugwell and Greenwood, 1975). Pneumococcal antigen typing was carried out on positive specimens using group-specific and monospecific pneumococcal antisera (Statens Serum Institute, Copenhagen). Sputum specimens negative to pneumococcal antigen were then tested for antigen to Neisseria meningitidis group Y by CIE using Difco antiserum. Percutaneous lung aspirations were obtained in 11 patients by rapidly inserting a 19-gauge needle into the consolidated area of the lung during suspended respiration while exerting negative pressure on the attached $5 \mathrm{ml}$ syringe.

Standard laboratory methods identified bacterial isolates from sputum, pleural fluid, and lung aspirates. The diagnosis of significant pneumococcal infection was based on the finding of pneumococcal antigen in purulent sputum or serum or the isolation of pneumococci from lung aspirates.

\section{ISOLATION OF M PNEUMONIAE}

Throat swabs from 70 patients were placed in complete $M$ pneumoniae broth and stored at $-20^{\circ} \mathrm{C}$ for up to one week before titration and incubation in liquid mycoplasma broth and subsequent subculture on to similar solid medium (Chanock et al, 1962).

$M$ pneumoniae was identified by: (a) slow growth rate, (b) colonial appearance, and (c) growth inhibition test (Black, 1973) using hyperimmune anti-M pneumoniae serum (FAO/WHO Centre for Animal Mycoplasmas, University of Aarhus, Denmark).

\section{SEROLOGICAL TESTS}

Blood was taken from all patients and allowed to clot at $37^{\circ} \mathrm{C}$ before storing the serum at $-20^{\circ} \mathrm{C}$. Aliquots of all sera were frozen and transported to Britain by air, but temporary thawing was often inevitable. On arrival they were stored at $-40^{\circ} \mathrm{C}$. A $M$ pneumoniae complement fixation (CF) test was performed on all sera using the method of Bradstreet and Taylor (1962) adapted to microtitre apparatus. Specific $M$ pneumoniae IgM was measured by a fluorescent antibody test (FAT) by Dr B E Andrews at the Mycoplasma Reference Laboratory, Norwich (Sillis and Andrews, 1978). This test was performed on all sera from patients who had: (a) a four-fold or greater rise in CF titre, (b) a single CF titre of $>1 / 64,(c) M$ pneumoniae isolated from the throat swab, or $(d)$ a cold agglutinin titre of $>1 / 32$. The diagnosis of current $M$ pneumoniae infection was accepted if the CF antibody titre rose four-fold during convalescence, or if the $M$ pneumonia-specific IgM FAT was $\gg 1 / 8$ (Andrews, personal communication). The isolation of $M$ pneumoniae in the absence of serological changes was taken to indicate recent infection, although not necessarily implicating $M$ pneumoniae as the primary cause of the current pneumonia. Sera from 13 patients, thought clinically to have a viral type of infection, were tested for antibody to influenza A and B, adenovirus, parainfluenza, $Q$ fever, and psittacosis antigens by the CF test. Serological evidence indicating influenza $A$ infection was confirmed by detecting influenza A-specific IgM by FAT (Urquhart, 1974). The latest specimen of serum from each patient was examined for evidence of legionnaires' disease by testing for specific IgM and IgG by FAT using a sero group 1-Legionella pneumophila antigen.

Specific IgM tests were considered valid only if the latex slide agglutination test for rheumatoid factor was negative.

\section{COLD AGGLUTININS}

A cold agglutinin screening test (CAST) (Garrow, 1958) was performed immediately on each blood sample; a positive result was recorded only if agglutination was obvious. Fifty fit adult Nigerians ( 35 men and 15 women) awaiting elective surgery were used as controls for cold agglutinin titres (C.AT) and CAST. The CAT were measured in one batch in Zaria at the end of the study by a microtitre method using a $2 \%$ suspension of $N_{\omega}^{N}$ washed fresh group 0 adult red cells containing $1 \%$ bovine serum albumin. After overnight incu- 0 bation at $4^{\circ} \mathrm{C}$, the titres were read "blind" by two observers.

\section{Results}

An aetiology for the lobar pneumonia was found in 51 out of 74 patients $(73 \%)$ as summarised in the table. 
Micro-organisms associated with lobar pneumonia in 74 patients. (Number with mixed infections in parentheses)

\begin{tabular}{|c|c|c|c|}
\hline Micro-organism & $\begin{array}{l}\text { No of } \\
\text { patients }\end{array}$ & Micro-organism & $\begin{array}{l}\text { No of } \\
\text { patients }\end{array}$ \\
\hline S pneumoniae & $37(7)$ & Tuberculosis & 2 \\
\hline $\begin{array}{c}M \text { pneumoniae } \\
\text { Diagnosed by } \\
\text { serology }\end{array}$ & $\begin{array}{r}12(6) \\
8(3)\end{array}$ & $\begin{array}{l}\text { Staphylococcus aureus } \\
\text { Salmonella para- } \\
\text { typhoid } C_{1}\end{array}$ & $\begin{array}{l}1 \\
1\end{array}$ \\
\hline $\begin{array}{l}\text { Diagnosed by } \\
\text { isolation alone }\end{array}$ & $4(3)$ & $\begin{array}{l}\text { Legionella } \\
\text { pneumophila }\end{array}$ & 0 \\
\hline Klebsiella species & 3 & $\begin{array}{l}N \text { meningitidis } \\
\text { group Y }\end{array}$ & $\mathbf{0}$ \\
\hline Influenza A & $3(2)$ & No aetiology found & 23 \\
\hline
\end{tabular}

\section{STREPTOCOCCUS PNEUMONIAE}

Thirty-seven patients $(50 \%)$ with lobar pneumonia had evidence of pneumococcal infection, and one died. Of these, nine $(24 \%)$ had pneumococcal antigenaemia and nine had received prior antibiotics. Lung aspirate cultures confirmed pneumococcal infection in three patients who had pneumococcal antigen in their sputum. Serotyping was performed on 17 sputum and eight serum samples found to contain pneumococcal antigen, and in all cases the type of antigen detected in the sputum was the same as that found in the blood for any particular patient. The types found included (number of cases in parentheses): 1 (3); $2 / 4$ (2); 3 (5); 5 (2); 12 (1-patient died); 18 (2); 21 (1); 41 (1); and 46 (1).

\section{PNEUMONIAE}

$M$ pneumoniae infection was found in 12 patients $(17 \%)$ out of the 70 investigated. The diagnosis was serological in eight patients, three of whom had a four-fold rise in CF titre (from $1 / 8$ to $1 / 32$, $1 / 16$ to $1 / 64$, and $1 / 64$ to $1 / 256$ ). In four cases where only an initial serum sample was available the CF titres were between $1 / 32$ and $1 / 256$, and the remaining patient had an unchanging $C F$ titre of $1 / 16$. In all these patients except one, who had a rising titre, mycoplasma-specific IgM was detected at titres between $1 / 8$ and $1 / 32$.

$M$ pneumoniae was isolated from throat swabs of a further four patients whose serology was not diagnostic. Mycoplasma species other than $M$ pneumoniae were isolated from 13 throat swabs.

The clinical, radiological, and laboratory features of patients with $M$ pneumoniae lobar pneumonia were similar to those of patients with pneumococcal lobar pneumonia.* Relatively more cases of $M$ pneumoniae infection were seen in the dry season, when lobar pneumonia from any cause was common (fig 1).

*Detailed table available from the authors.

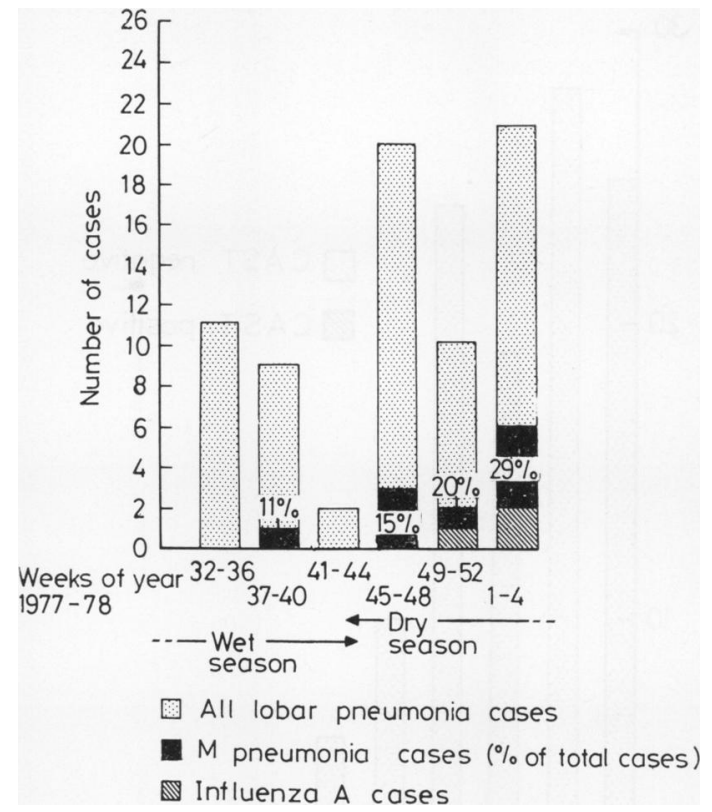

Fig 1 Seasonal incidence of lobar pneumonia cases.

Cold agglutinin titres are displayed in fig 2 . Patients with serological evidence of $M$ pneumoniae infection tended to have higher titres, although the difference is not significant. The CAST picked out some of the cases with higher CAT (fig 3).

\section{MIXED INFECTIONS}

Associated pneumococcal infection was found in six $(50 \%)$ patients with $M$ pneumoniae infection. Three had pneumococcal antigenaemia.

\section{OTHER BACTERIA}

No cases of legionnaires' disease or meningococcal group $\mathrm{Y}$ infection were detected. Pulmonary tuber-

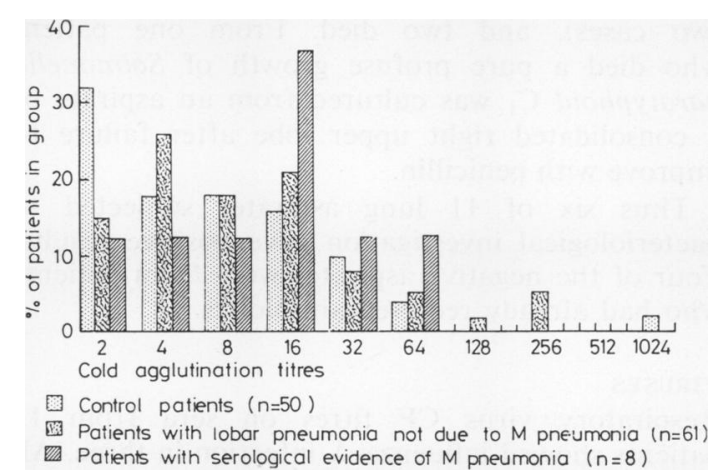

Fig 2 Maximum cold agglutinin titres recorded for patients with lobar pneumonia. 


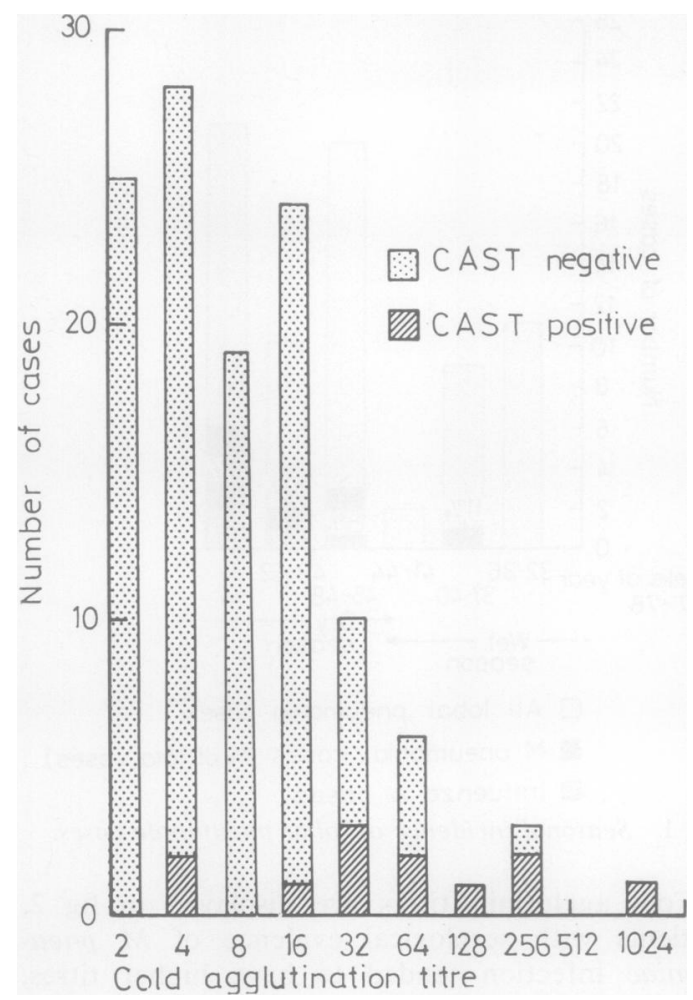

Fig 3 Results of cold agglutinin screening test (CAST) compared with cold agglutinin titre of same blood sample for patients and controls.

culosis was subsequently diagnosed in two patients who presented with upper lobe segmental consolidation. One 10-year-old boy who died shortly after admission had Staphylococcus aureus grown from ante-mortem blood cultures and post-mortem consolidated lung tissue. Three patients had Klebsiella infection confirmed by culture of lung aspirates (in two cases) and/or pleural fluid (in two cases), and two died. From one patient who died a pure profuse growth of Salmonella paratyphoid $\mathbf{C}_{1}$ was cultured from an aspirate of a consolidated right upper lobe after failure to improve with penicillin.

Thus six of 11 lung aspirates subjected to bacteriological investigation gave positive results. Four of the negative aspirates were from patients who had already received antibiotics.

\section{VIRUSES}

Respiratory virus CF titres on sera from 13 patients showed influenza $A$ infection in three. All three occurred in the cooler part of the dry season (fig 1). One patient had associated pneumo- coccal antigenaemia and $M$ pneumoniae was isolated from the throat of another.

FOLLOW-UP

Sixty-seven per cent of survivors attended for follow-up, and most were well or had minor complaints. Five patients had not improved significantly despite treatment. Four of these had had pneumococcal antigenaemia on presentation, two associated with $M$ pneumoniae infection and one with influenza $A$ infection. The fifth patient had serological evidence of $M$ pneumoniae infection only and developed arthritis of the left elbow two months after initial presentation.

\section{Discussion}

Pneumococcal infection is confirmed as the commonest cause of lobar or segmental pneumonia in a tropical environment. It was diagnosed in $50 \%$ of our patients, similar to other studies from Nigeria (Tugwell and Greenwood, 1975) and New Guinea (Douglas and Riley, 1970).

CIE proved to be a convenient and quick method of detecting pneumococcal antigen in purulent sputum. This is a more accurate indication of lower respiratory tract invasion than sputum culture for pneumococci (Tugwell and Greenwood, 1975; Wiernik et al, 1978) as the latter is often misleading (Barrett-Connor, 1971). The pathogenic relevance of pneumococcal antigen in the sputum is confirmed by our finding identical serotypes in the blood and sputum of the same patients. The serotypes found were similar to reports from here five years ago (Tugwell and Greenwood, 1975), suggesting a stable type incidence that is important when contemplating protection of the community by pneumococcal vaccine.

Transtracheal or lung aspirates are rewarding techniques for diagnosing bacterial infection, though not without risk (Davidson et al, 1976), and lung aspiration has been used before successfully in developing countries (Douglas and Devitt, 1973; Silverman et al, 1977). We found the procedure safe and particularly useful in diagnosing non-pneumococcal bacterial lung infections including klebsiella and paratyphoid pneumonias.

The incidence of non-pneumococcal, bacterial pneumonias in developing countries is not known. $N$ meningitidis group $\mathrm{Y}$ has been implicated as a not infrequent but often unrecognised cause of pneumonia, especially after viral infection (Putsch et al, 1970; Jacobs and Norden, 1974), and it has been suggested that meningococcal vaccination as practised widely in Finland (Nikoskelainen et al, 1978) and recently successfully used in northern 
Nigeria (Greenwood et al, 1978) may select out Meningococcus $\mathrm{Y}$ as a serious respiratory pathogen (Nikoskelainen et al, 1978). It is thus encouraging that this pathogen was not found in the sputum of our patients. Similarly, although legionnaires' disease is an increasingly reported respiratory illness in the USA and UK (Bartlett, 1979), no such infection was detected in our series. We have found no other reports of legionnaires' disease in Africa.

Evidence of $M$ pneumonia infection in $17 \%$ of our cases with lobar pneumonia shows that this micro-organism is as prevalent in tropical Africa as in developed countries (Chanock, 1965; Foy et al, 1970) and ranks second to pneumococcus as the commonest cause of pneumonia. As pneumonia occurs in less than $10 \%$ of infected individuals (Chanock et al, 1961), our figures suggest that it is also likely to be a frequent cause of upper respiratory tract infections in Zaria. The serological titres found in our patients are lower than are normally expected, and this is probably due to suboptimal storage conditions of the sera, especially during transport to Britain.

$M$ pneumoniae was isolated from the throats of four patients without serological changes; a diagnostic criterion of infection used before in large series (Mufson et al, 1967; Foy et al, 1970). Because isolation from the nasopharynx is possible for several weeks after an infection (Grayston et $a l, 1965)$, despite appropriate antibiotics, isolation alone can only be regarded as evidence of recent infection and does not necessarily implicate $M$ pneumoniae as the primary pathogen of the current pneumonia. It is, nevertheless, possibly an important factor in the development of that pneumonia as half of our patients with $M$ pneumoniae infection had associated pneumococcal infection and half of these had pneumococcal antigenaemia; a finding associated with more serious disease, slowed resolution, and a poor prognosis (Tugwell and Greenwood, 1975). Experimentally, prior $M$ pneumoniae respiratory tract infection has been shown to predispose to the development of pneumococcal pneumonia and septicaemia in hamsters (Liu et al, 1972) and occasionally bacterial pneumonias are reported complicating $M$ pneumoniae infection in man (Hers, 1968; Stadel et al, 1975). $M$ pneumoniae infection probably renders the lung vulnerable to subsequent bacterial infection in several ways. Bronchial ciliary action is lost, impairing tracheobronchial clearance of inhaled foreign particles (Jarstrand et al, 1974) and cellular immunity is depressed (Adegboye, 1978). Thus concurrent $M$ pneumoniae infection should be thought of in patients in tropical Africa whose pneumococcal lobar pneumonia is responding slowly for no obvious reason and a change in antibiotics to include erythromycin or tetracycline should be considered.

We found no difference in the clinical or radiological presentation of our patients with lobar pneumonia associated with pneumococcal or $M$ pneumoniae infection. In particular nonrespiratory complaints, such as arthralgia, sore throat, diarrhoea, and vomiting, were equally common in both groups. At follow-up relatively more of the patients with $M$ pneumoniae infection still had symptoms, especially when associated with pneumococcal antigenaemia, although the numbers were too small to draw firm conclusions.

Although CIE of sputum has been disappointing in the early diagnosis of $M$ pneumoniae pneumonia (Wiernik et al, 1978), CATs can be useful, as they may be raised in up to $70 \%$ of cases (Chanock, 1965). In this study there was no significant difference in CATs in patients with or without evidence of $M$ pneumoniae infection. Cold haemagglutination depends on the production of an IgM autoantibody to the erythrocyte $\mathrm{I}$ antigen during $M$ pneumoniae infection (Jacobson et al, 1973). Autoimmune diseases are uncommon in Nigerians, perhaps related to immunological disturbances produced by parasitic infections (Greenwood, 1968), and this may explain the poor autoantibody production in our patients with $M$ pneumoniae infection as reflected in low CATs.

The CAT, even if raised, is unlikely to be a reliable indication of $M$ pneumoniae infection in this area as we found 13 patients with no evidence of $M$ pneumoniae infection who had CATs ranging from 32 to 256 . It has been suggested that the high incidence of cold agglutinins found in groups living in a tropical environment is due partly to parasitic infections, especially malaria (Curtain et $a l$, 1965). The CAST (Garrow, 1958) was quick and simple. Our results did not confirm the absolute correlations with high titres found by the CA test, reported by Griffin (1969).

Lobar pneumonia in Nigeria is commoner in the dry season (Warrell, 1975), and this was also true for our cases of $M$ pneumoniae infection. The low absolute humidity at this time of the year probably damages the local defence mechanism of the nasopharynx. This drying of nasal secretion may impair local IgA activity, a factor known to be important in preventing infection by $M$ pneumoniae (Brunner et al, 1973).

Although the pneumococcus is the commonest cause of lobar pneumonia in the savanna region of northern Nigeria, there is a significant incidence of $M$ pneumoniae infection in addition to 
other less common bacterial and viral causes of pneumonia, and this must be borne in mind when planning outpatient treatment or considering management of non-resolving lobar pneumonia in the tropics.

We found no means of differentiating mycoplasmal from other pneumonias in time to be therapeutically useful. The use of CIE to detect $M$ pneumoniae antigen is being further investigated.

We thank Dr B M Greenwood of the MRC Immunology Unit, Zaria, for performing the CIE tests and Dr B E Andrews of the Public Health Laboratory Service Mycoplasma Reference Laboratory, Norwich, for measuring and interpreting $M$ pneumoniae-specific IgM. We are grateful for the help of the Departments of Haematology and Microbiology, Ahmadu Bello University, Zaria, and for advice from Dr D A Warrell.

\section{References}

Adegboye, D S (1978). A review of Mycoplasmainduced immunosuppresion. British Veterinary Journal, 134, 556-560.

Barrett-Connor, E (1971). The non-value of sputum culture in the diagnosis of pneumococcal pneumonia. American Review of Respiratory Disease, 103, 845-848.

Bartlett, C L R (1979). Sporadic cases of legionnaires' disease in Great Britain. Annals of Internal Medicine, 90, 592-595.

Black, F T (1973). Modifications of the growth inhibition test and its application to human T-Mycoplasmas. Applied Microbiology, 25, 528-533.

Bradstreet, C M P, and Taylor, C E D (1962). Technique of complement-fixation test applicable to the diagnosis of virus diseases. Monthly Bulletin of the Ministry of Health and PHLS, 21,96-104.

Brunner, H, Greenberg, H B, James, W D, Horswood, R L, Couch, R B, and Chanock, R M (1973). Antibody to Mycoplasma pneumoniae in nasal secretions and sputa of experimentally infected human volunteers. Infection and Immunity, 8, 612-620.

Chanock, R M (1965). Mycoplasma infections of man. New England Journal of Medicine, 273, 1257-1264.

Chanock, R, Chambon, L, Chang, W, Ferreira, F G, Gharpure, P, Grant, L, Hatem, J, Imam, I, Kalra, S, Lim, K, Madalengoitia, J, Spence, L, Teng, P, and Ferreira, W (1967). WHO respiratory disease survey in children. Bulletin of World Health Organisation, 37, 363-369.

Chanock, R M, Hayflick, L, and Barile, M F (1962). Growth on artificial medium of an agent associated with atypical pneumonia and its identification as a PPLO. Proceedings of National Academy of Science of USA, 48, 41-49.

Chanock, R M, Mufson, M A, Bloom, H H, James, W D, Fox, H H, and Kingston, J R (1961). Eaton agent pneumonia. Journal of the American Medical Association, 175, 213-220.

Curtain, C C, Baumgarten, A, Gorman, J, Kidson, C, Champness, L, Rodrigue, R, and Gajdusek, D C (1965). Cold haemagglutinins: unusual incidence in Melanesian populations. British Journal of Haematology, 11, 471-479.

Davidson, M, Tempest, B, and Palmer, D L (1976). Bacteriological diagnosis of acute pneumonia. Comparison of sputum, transtracheal aspirates and lung aspirates. Journal of the American Medical Association, 235, 158-163.

Douglas, R M, and Devitt, L (1973). Pneumonia in New Guinea. I Bacteriological findings in 632 adults with particular reference to Haemophilus influenza. Medical Journal of Australia, 1, 42-49 .

Douglas, R M, and Riley, I D (1970). Adult pneumonia in Lae-99 consecutive cases. Papua and New Guinea Medical Journal, 13, 105-109.

Foy, H M, Kenny, G E, McMahan, R, Mansy, A M, and Grayston, J T (1970). Mycoplasma pneumoniae pneumonia in an urban area, Five years of surveillance. Journal of the American Medical Association, 214, 1666-1672.

Garrow, D H (1958). A rapid test for the presence of increased cold agglutinins. British Medical Journal, 2, 206-208.

Griffin, J P (1969). Rapid screening for cold agglutinins in pneumonia. Annals of Internal Medicine, 70, 701-705.

Greenwood, B M (1968). Autoimmune disease and parasitic infections in Nigerians. Lancet, 2, 380-382.

Greenwood, B M, Hassan-King, M, and Whittle, H C (1978). Prevention of secondary cases of meningococcal disease in household contacts by vaccination. British Medical Journal, 1, 1317-1319.

Gupta, U, Vaishanava, S, and Gulati, A K (1975). Mycoplasma pneumoniae infections in infants and children. Indian Journal of Medical Research, 63, 385-389.

Hassan, A, Wahab, M F A, Zaghloul, I, Farid, Z, Shoeb, S M, and Labib, A (1972). A study of the aetiology of pneumonia in Egypt. Journal of the Egyptian Public Health Association, 47, 333-347.

Hers, J F P (1968). Clinical aspects of infection with Mycoplasma pneumoniae. Proceedings of the Royal Society of Medicine, 61, 1325-1330.

Jacobs, S A, and Norden, C M (1974). Pneumonia caused by Neisseria meningitidis. Journal of the American Medical Association, 227, 67-68.

Jacobson, L B, Longstretch, G F, and Edgington, T S (1973). Clinical and immunological features of transient cold agglutinin hemolytic anemia. American Journal of Medicine, 54, 514-521.

Jarstrand, C, Camner, P, and Philipson, K (1974). Mycoplasma pneumoniae and tracheobronchial clearance. American Review of Respiratory Disease, $110,415-419$.

Joosting, A C C, Battaglia, P, and Gear, J H S (1975). Mycoplasma pneumoniae infection. South African Medical Journal, 49, 998. 
Kitamoto, O, Nakamura, S, Ebisawa, I, and Sato, T (1966). Mycoplasma pneumoniae infection in atypical pneumonia in the Tokyo area. Japanese Journal of Experimental Medicine, 36, 291-299.

Liu, C, Jayanetra, P, Voth, D W, Muangmanee, L, and Cho, C T (1972). Potentiating effect of Mycoplasma pneumoniae infection on the development of pneumococcal septicaemia in hamsters. Journal of Infectious Diseases, 125, 603-612.

Mufson, M A, Chang, V, Gill, V, Wood, S C, Romansky, M J, and Chanock, R M (1967). The role of viruses, mycoplasmas and bacteria in acute pneumonia in civilian adults. American Journal of Epidemiology, 86, 526-544.

Nikoskelainen, J, Lähtönen, E, Leino, A, Kalliomäki, J L, and Toivanen, A (1978). Is group-specific meningococcal vaccination resulting in epidemics caused by other groups of virulent meningococci? Lancet, 2, 403-405.

Putsch, R W, Hamilton, J D, and Wolinsky, E (1970). Neisseria meningitidis, a respiratory pathogen? Journal of Infectious Diseases, 121, 48-54.

Sillis, M, and Andrews, B E (1978). A simple test for Mycoplasma pneumoniae IgM. Zentralblatt für Bakteriologie, Parasitenkunde, Infektionskrankheiten und Hygience Originale Ser A, 241, 239-240.

Silverman, M, Stratton, D, Diallo, A, and Egler, L J (1977). Diagnosis of acute bacterial pneumonia in Nigerian children. Value of needle aspiration of lung and of counter current immuneoelectrophoresis. Archives of Diseases of Childhood, 52, 925-931.

Sofowara, E O, and Onadeko, B O (1973). Complications and prognostic factors in pneumonia among
Nigerians. Nigerian Medical Journal, 3, 144-145.

Stadel, B V, Foy, H M, Nuckolls, J W, and Kenny, G E (1975). Mycoplasma pneumoniae infection followed by Haemophilus influenzae pneumoniae and bacteremia. American Review of Respiratory Disease, 112, 131-133.

Sutton, D R, Wicks, A C B, and Davidson, L (1970). One-day treatment for lobar pneumonia. Thorax, 25, 241-244.

Tai, F, and Wei, H (1976). Mycoplasmal pneumonia in Chinese veterans. Chinese Journal of Microbiology, 9, 5-12.

National Academy of Sciences (1962). Tropical Health. National Research Council Publication 996, 34. Washington, USA.

Tugwell, P, and Greenwood, B M (1975). Pneumococcal antigen in lobar pneumonia. Journal of Clinical Pathology, 28, 118-123.

Urquhart, G E D (1974). Serum IgM and IgA responses in influenza A infections. Journal of Clinical Pathology, 27, 198-201.

Warrell, D A (1975). Respiratory tract infections in the tropics. Practitioner, 215, 740-746.

Wiernik, A, Jarstrand, C, and Tunevall, G (1978). The value of immunoelectro-osmophoresis (IEOP) for aetiological diagnosis of acute respiratory tract infections due to pneumococci and Mycoplasma pneumoniae. Scandanavian Journal of Infectious Diseases, 10, 173-176.

Requests for reprints to: J T Macfarlane, Department of Thoracic Medicine, City Hospital, Hucknall Road, Nottingham NG5 1PB. 